\title{
Reconnecting a Fragmented Monument through Digital Mapping: The City Walls of Athens
}

\author{
MARKOS KATSIANIS, STAMATINA LAMPRAKI, ANNA MARIA THEOCHARAKI, \\ MARIA PIGAKI, LEDA COSTAKI and EVANTHIA PAPAEFTHIMIOU \\ Dipylon, Society for the Study of Ancient Topography, Greece
}

\begin{abstract}
The fortifications of Athens have been a recurrent object of archaeological investigation. In the past two centuries, parts of the walls have been located during rescue interventions at numerous sites in the urban fabric. At present, the visibility of the entire monument remains rather low as the traces of the walls are hidden beneath the modern city, marginalized within larger archaeological sites, or preserved solely by the written record. Despite the high level of scholarly work devoted to synthesizing the available material, the volume of information accumulated over the years requires an integrated approach that would systematize different types of evidence using digital media. To this end, we attempt to revisit the city walls of Athens through the use of geospatial technologies. Our aim is the informed development of an efficient digital mapping platform to record, store, combine, explore and eventually disseminate resources about the fortifications of Athens. Our research employs published and archival sources (e.g., excavation drawings) in combination with historical maps (e.g., early cadastral maps, the earliest maps of modern Athens) and complementary historical evidence (e.g., writings, illustrations, photography) to locate, document and integrate in space and time available data on lost and surviving fortification remains.
\end{abstract}

Key words:

Urban Archaeology, GIS, Historical Maps, Fortifications, Athens, Greece.

\section{SDH Reference:}

Markos Katsianis et al. 2018. Reconnecting a Fragmented Monument through Digital Mapping: The City Walls of Athens. SDH, 2, 2, 177-195.

DOI : $10.14434 /$ sdh.v2i2.24440

\section{INTRODUCTION}

The city walls of Athens have been a constant object of antiquarian and archaeological investigation ever since the 17th and 18th centuries, when early travelers visited Athens to explore the surviving ancient remains [Lagogianni-Georgakarakos and Koutsogiannis 2015]. Interest in the walls is easily comprehensible: important in themselves, they also defined the extent of the largely vanished ancient city. Throughout the 19th century, several scholars studied the traces of the ancient wall to establish the fortification line and the location of the gates as mentioned in the ancient texts. In the latter part of the 19th and for most of the 20th century, archaeological research started unearthing

Author's address: Markos Katsianis, Stamatina Lampraki, Anna Maria Theocharaki, Maria Pigaki, Leda Costaki and Evanthia Papaefthimiou, Dipylon - Society for the Study of Ancient Topography, 20 Omirou Str, 106 72, Athens, Greece; email: info@dipylon.org.

(C) [2018] by the authors; licensee Studies in Digital Heritage, IU, Bloomington (IN), USA. This article is an open access article distributed under the terms and conditions of the Creative Commons Attribution License (CC BY-NC). 
new sections of the wall. At the beginning of the 21st century the completion of major public works (such as the Athens Metro or the Unification of the Archaeological Sites of Athens) raised the issue about the preservation and enhancement of the surviving wall sections.

Despite the massive corpus of data about the city walls compiled during the last two centuries [Theocharaki 2011, 2015], their investigation is still inhibited by a number of factors:

a) Successive wall building phases did not necessarily follow the pre-existing courses. This has resulted in a series of different fortification lines. Physical remains of the walls exhibit diverse structural characteristics, masonry techniques and materials used, while their state of preservation, use, and the history of their degradation and decay are highly variable.

b) Investigation has been carried out in a fragmentary manner impeding the overall study of the monument. Several sections of the wall were retrieved in different periods, some in the framework of long-term archaeological projects (e.g., the area of the Dipylon Gate in the Kerameikos). The great majority of physical remains of the wall have been recovered during short-term rescue operations taking place during the process of urban development.

c) The Athenian walls have not been conceptualized as a monument in their entirety, in contrast to other cities (such as Thessaloniki or Rhodes) where the remains are so well preserved that they endure as a formative element of the modern urban landscape. Surviving bits and pieces lie in various parts of the city, either within protected archaeological sites or preserved in situ in the foundations of public or private buildings. Their overall management and state of preservation is, accordingly, case specific.

d) Finally, the documentation record of the walls is disparate in terms of information provided. Moreover, it is dispersed in different sources that range from reports of rescue excavations, usually in the form of preliminary research summaries, to unpublished records. The language used is mostly Greek.

Any attempt to approach the fortifications of Athens in their entirety and to explore their modern cultural significance and effect on the contemporary urban fabric would need to trace their diachronic transformations and assess their past and present visibility both as a spatial and temporal city boundary (Fig. 1). Towards this end, Geographic Information Systems (GIS) and digital mapping tools have been employed to integrate all available data on the walls into a single knowledge platform in order to locate in space and connect in time all the physical remains and footprints of the Athenian fortifications. From this point of view, this paper is a case study for enhancing urban archaeology results through interdisciplinary research including Archaeology, History and Geoinformatics, with a view to re-activating the memory of place for one of the most investigated, albeit least known historic monuments of the city. 


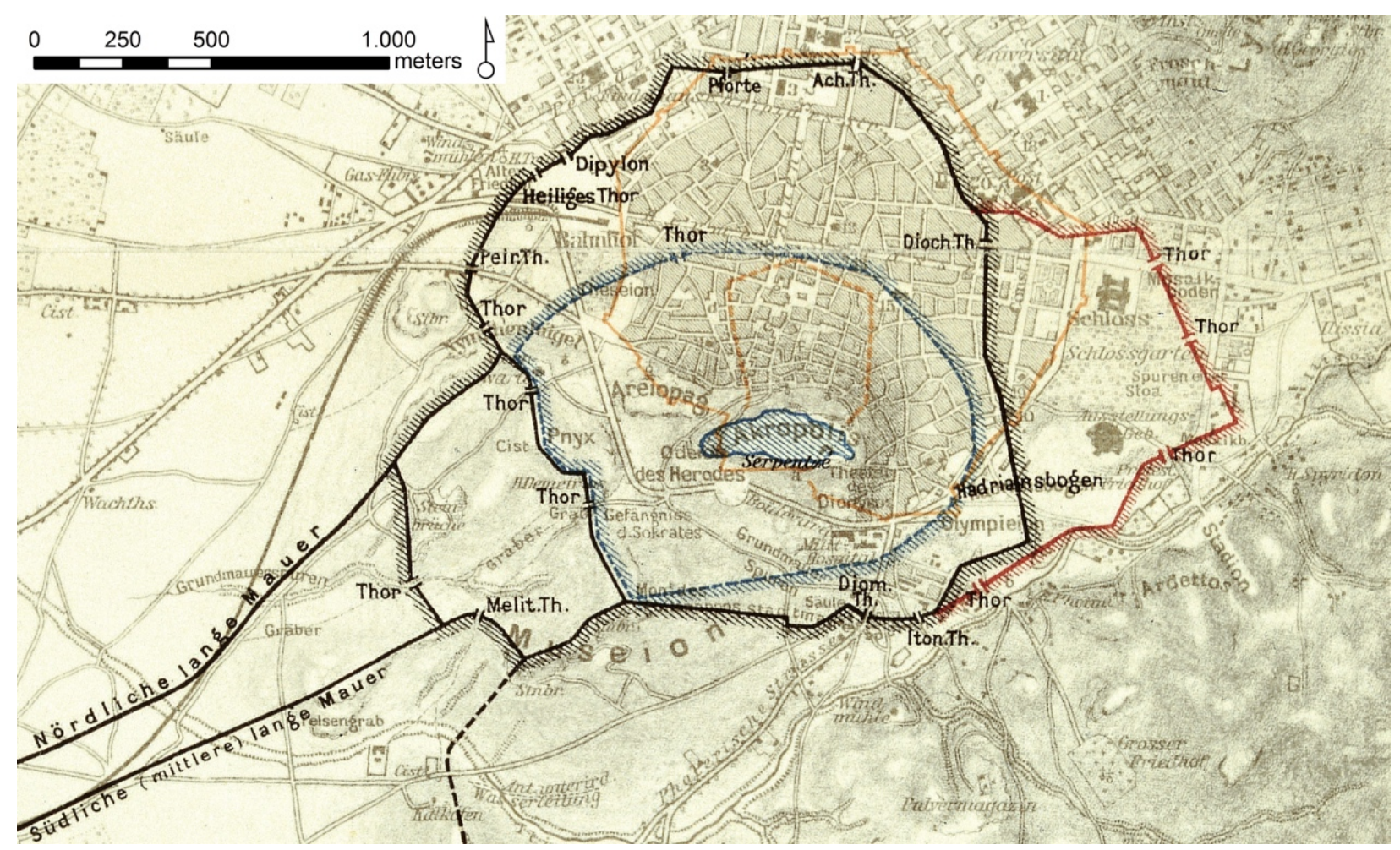

Figure 1. Georeferenced detail of map by Judeich [1931: Plan IV] depicting the estimated courses of successive fortification lines.

\section{SCOPE, SOURCES AND DATA}

The main data sources to be combined within this framework include archaeological reports, cartographic evidence and historical accounts and representations. The process of integrating a variety of data sources allows for increased spatial accuracy and greater temporal resolution; it may also enhance the information capacity of the overall content with respect to the diachronic transformations and modern preservation of this dispersed monument. As a result, the use of geospatial technologies, historical maps and graphical representations has the potential to identify archaeological remains and track different construction phases in their recent history as heritage assets.

Both open source (QGIS) and commercial (ArcGIS) software has been employed in this project. Spatial and thematic data from previous projects in CAD and GIS formats [Costaki 2006; Theocharaki 2015] were cleaned and migrated into a new data structure contained within a geodatabase.

\subsection{Archaeological record}

With regard to Archaeology, the published material about the city walls is primarily contained in excavation reports of interventions at specific land plots prior to residential development and 
infrastructure works (typically found in the annual volumes of the Archaiologikon Deltion). In addition, several scholars have brought together the results of archaeological research at Athens in a number of synthetic works [Judeich 1931; Travlos 1971; Karydis 1981; Vavylopoulou-Charitonidou et al. 1988; Costaki 2006; Tsoniotis 2008; Demetriadou 2012; Theocharaki 2011, 2015], or in volumes with the results of major research projects, such as the Athens Metro excavations [Parlama and Stampolidis 2001]. Unpublished material can also be traced in personal papers of individual archaeologists, housed in the Historical Archives of the Archaeological Service and the Archives of the Archaeological Society at Athens. Often, the only surviving records are rough drawings or sketches, alongside handwritten notes kept in personal notebooks or correspondence.

The goal of this part of the project is to specify the exact location of the archaeological interventions that retrieved fortification remains-regardless of the type of preservation-on the modern city canvas. The excavation plans that accompany archaeological reports have been registered as accurately as possible with respect to the layout of the modern city. Their graphical information is broken up into features of interest (e.g., wall, moat, drain), that have been individually vectorized (Fig. 2).

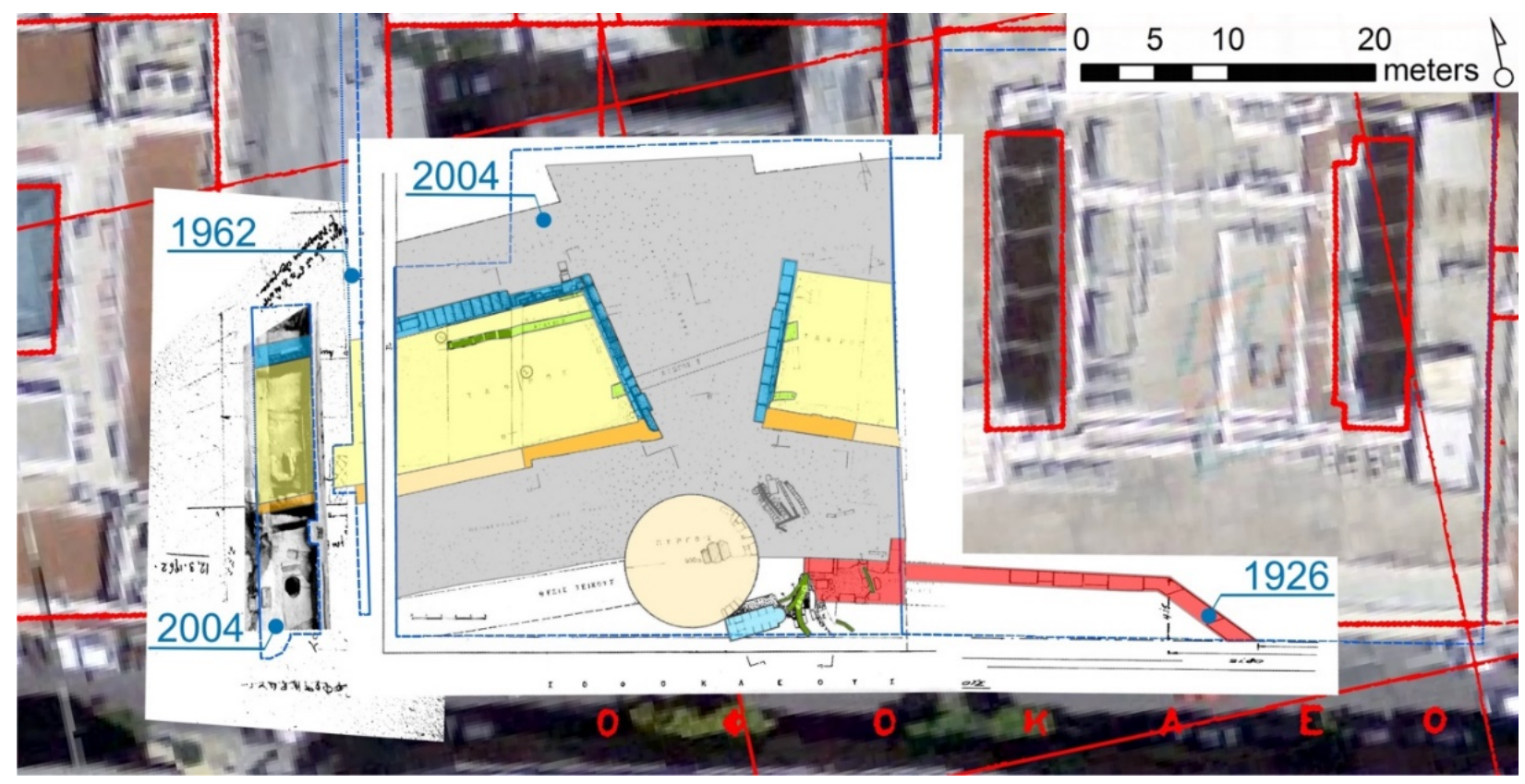

Figure 2. Sophokleous and Aiolou Streets. Digitized excavation features on top of original georeferenced excavation plan drawings and orthophotos from four distinct archaeological interventions. Basemap data include the cadastral distribution by the Ministry of Public Works 1972-76.

Relevant fortification types and components have been established through the combination of synthetic studies [Theocharaki 2015], architectural dictionaries [Orlandos and Travlos 1986; Ginouvès 1998; Ginouvès and Martin 1985], and further correlated with terms from Online Thesauri [Getty Research Institute 2018; Forum on Information Standards in Heritage 2019]. Obviously, in cases where excavation plans cannot be accurately located or are even completely missing, the aim is to extract 
features of interest mentioned in the excavation report and to situate the boundaries of the intervention, in order to associate excavation information with specific locations. Every feature located and mentioned in a site report is then supplemented by thematic and chronological information, state of preservation and present condition assessment allowing their exploration and on-screen selection on the map (Fig. 3).

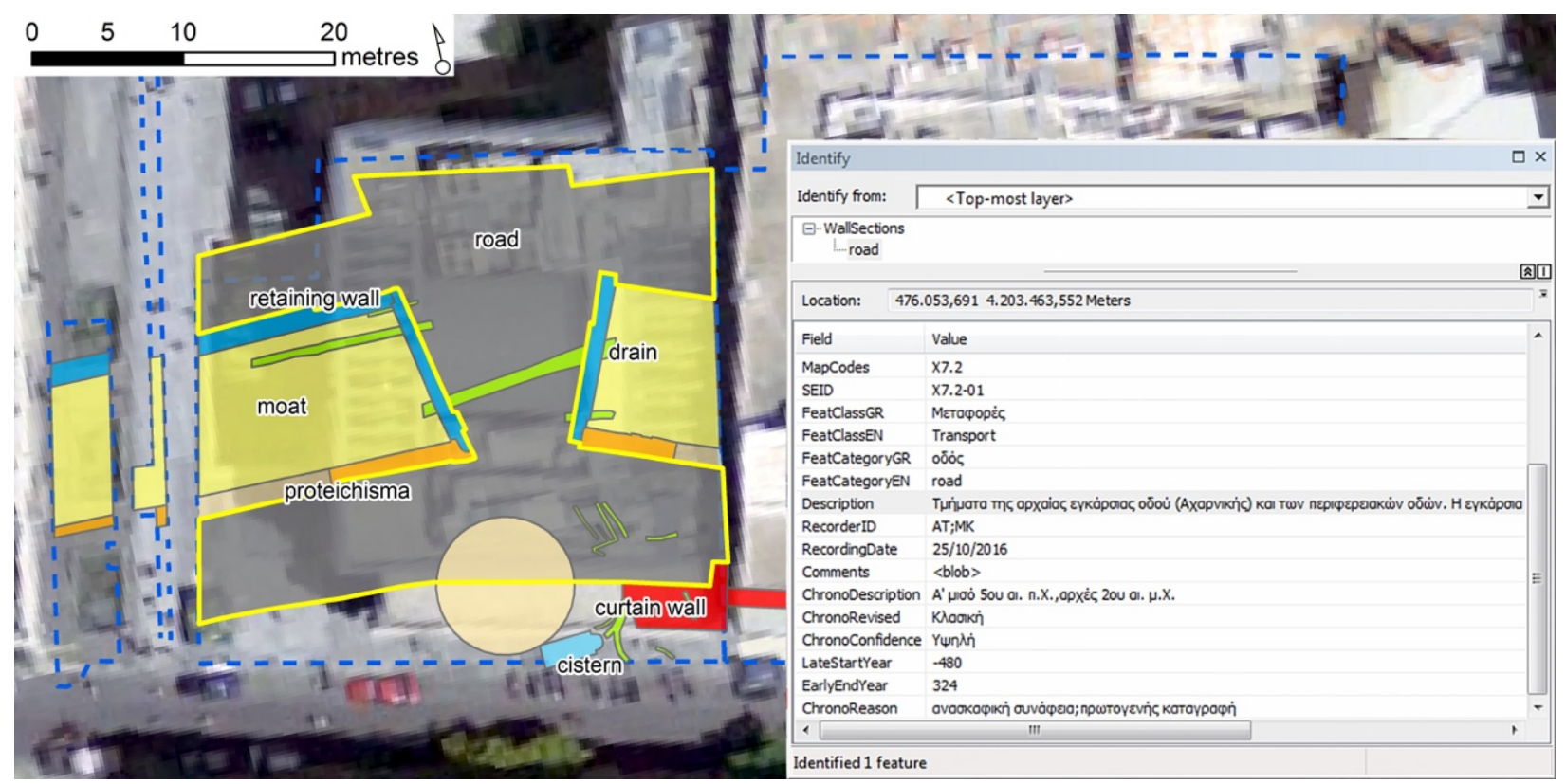

Figure 3. Sophokleous and Aiolou Streets. Digitized excavation features labeled by type. Example of on-screen selection and display of thematic attributes.

\subsection{Cartographic sources}

With respect to cartographic evidence, the sources include cadastral distributions, urban planning records and old city maps. Perhaps the biggest problem for combining all this evidence and bringing it up to date is the existence of a number of different national coordinate systems that have been used successively and in parallel throughout Greece in the last two centuries [Scollar 2002]. Despite the establishment of the National Observatory in 1842 as an origin for most of these coordinate systems, their definition used different datums and projections. There are also examples where work was carried out on local grids. In this project, we proceeded in a piecemeal fashion; we have started from the latest available sources moving backwards in order to re-project them into a common coordinate system, in this case the "Greek Grid Reference System" (GGRS87, EPSG:2100). In all cases, the transformation scheme was selected on the basis of the density and the spatial distribution of the available control points [Boutoura and Livieratos 2006].

The most recent cartographic source is the cadastral distribution of a scale of 1:1000 in $3^{\circ}$ Transverse Mercator Projection by the Ministry of Public Works 1972-76 for the city of Athens. We used 16 map sheets (TM3) that provide full coverage of all fortification courses. Each sheet contains a line grid, with an interval of $50 \mathrm{~m}$, whose intersections can be used for the georeferencing procedure. Out of 
the 130 intersections in each map sheet, 86 can optimally be used in order to achieve a mean RMS error less than the minimum mapping unit, which derives from the scale of the map sheets. The spline transformation is considered as the most suitable in order to fine-tune inaccuracies related to inherent analogue map deformations or scanning related distortions. Owing to the equal distribution of the control points, this choice gives precise correspondence with the grid, avoids straight line curvatures and allows for the seamless joining of adjacent map sheets (Fig. 4). The entire raster collection provides a snapshot of the urban development in the 1970s and is directly comparable to the fully orthorectified satellite imagery with GSD $0.20 \mathrm{~m}$ for urban/built-up areas of the country, provided by the "National Cadastre and Mapping Agency S. A." (NCMA) (http://gis.ktimanet.gr/wms/ktbasemap/). Their dataset is openly available and has been used as the main satellite basemap in figures included here, unless otherwise stated.

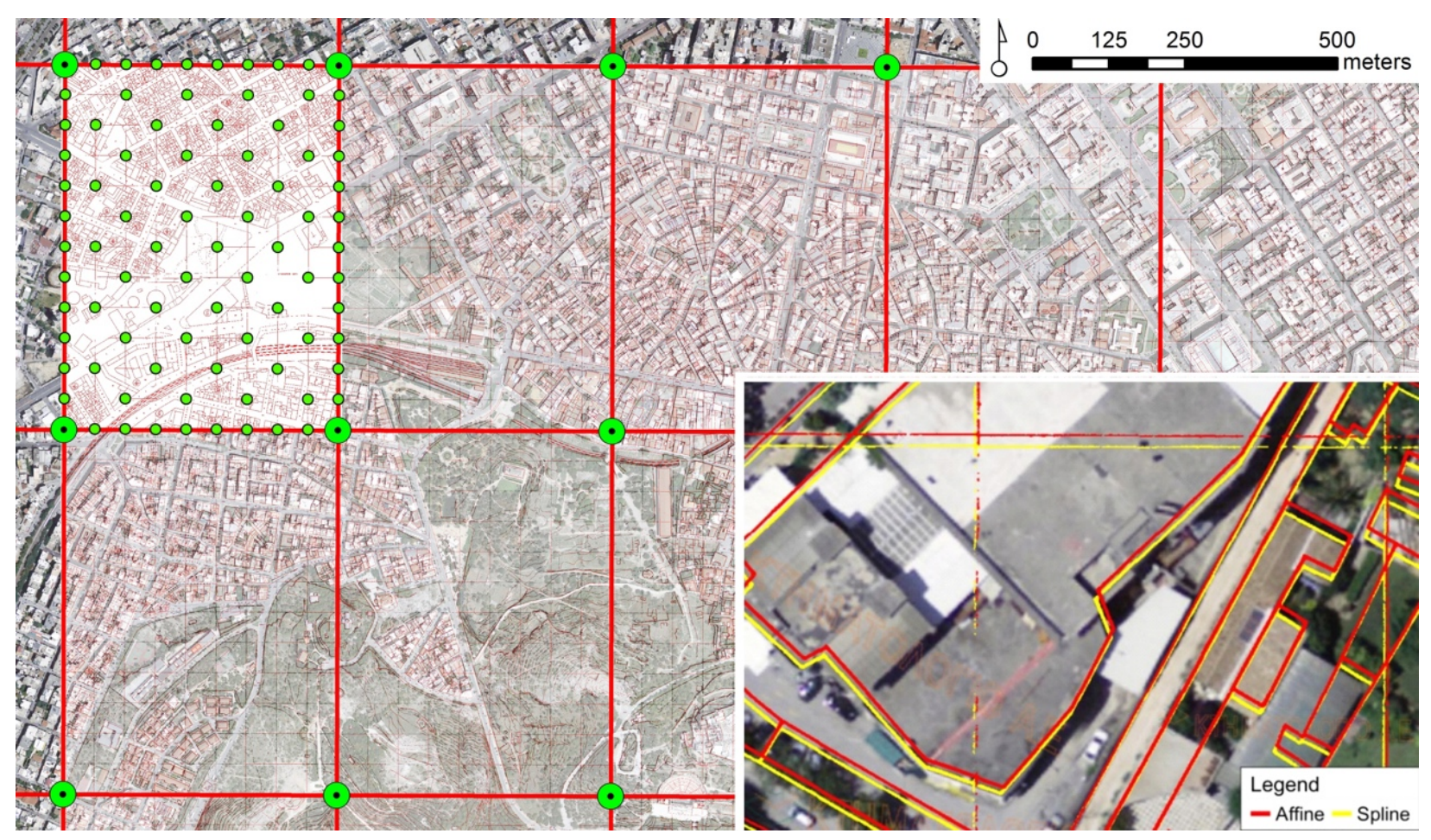

Figure 4. Part of the georeferenced raster collection of the 1972-76 cadastral distribution (Ministry of Public Works) for the center of Athens. Distribution of points used in the georeferencing process is indicated at the top left map sheet, while the results of spline and affine transformations are compared in relation to satellite imagery (detail at bottom right).

Earlier cartographic evidence derives from the cadastral registration before 1936, held by the Division of City Planning and Urban Development of the Municipality of Athens (MoA) at a scale of 1:500 and in local grid based on the National Observatory of Athens. We used 25 map sheets that refer to locations with fortification evidence from different periods. This distribution lacks in regularity when compared to subsequent mappings: each sheet contains a line grid with an interval of $50 \mathrm{~m}$. The georeferencing procedure involves the re-projection of the local grid to GGRS87 and the pairing 
of the grid's intersections on the map sheets with the corresponding on the re-projected grid, achieving an average global affine "Root-Mean-Square" (RMS) error $<0.50 \mathrm{~m}$. The spline transformation accounts for map deformations related to the bad condition of the originals (rips and crumples). Having the same regular distribution of control points and using all available points (usually between 45 and 56, depending on map readability), the spline function succeeded in precisely placing the map grid points, while avoiding the addition of local noise (Fig. 5).

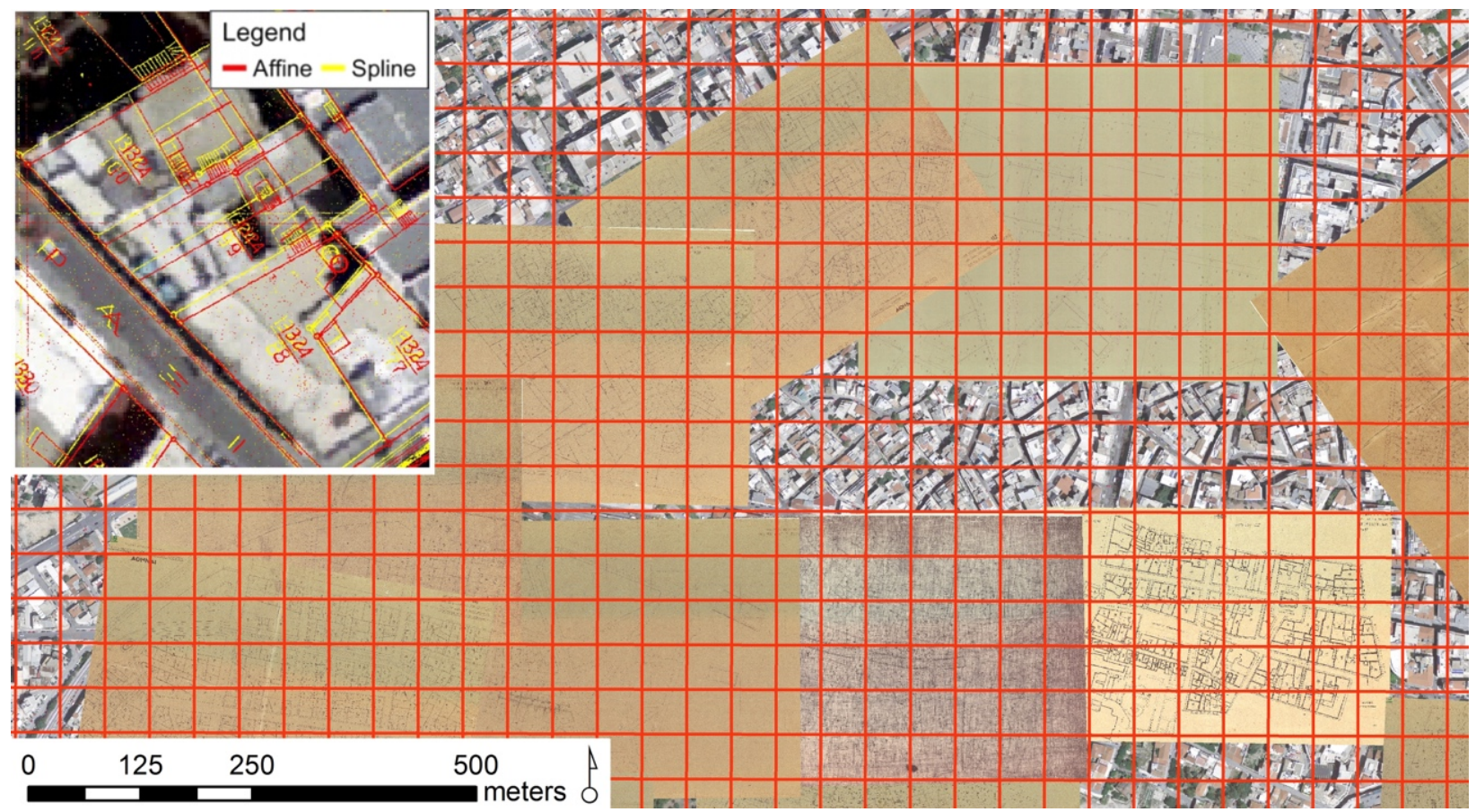

Figure 5. Part of the georeferenced raster collection of the pre-1936 cadastral distribution (Division of City Planning and Urban Development, MoA). Example of spline and affine transformations overlying the satellite imagery (detail at top left).

Further back in time, the monumental cartographic work in "Karten von Attika" by Curtius and Kaupert [1881] contains one map sheet of the city of Athens, at the scale of 1:12500. Although Livieratos et al. [2013] have attempted to establish a framework for the digital approach of the entire set of 1:25000 maps of Attica, their discussion is rather limited in relation to the georeferencing of the city of Athens sheet (I). Despite its relatively small scale, its information potential is substantial, as the drawing quality of the map renders several topographic and archaeological details sufficiently discernible. The original publication of Curtius and Kaupert (discussed and appraised by Korres [2008]) contains the local coordinates (XYZ) of 30 trigonometric points, among which 25 can be accurately located on the map. The georeferencing was performed by re-projecting the above local coordinate system to GGRS87, and not by pairing corresponding points between the map and a modern basemap. The accuracy of the majority of the re-projected trigonometric points, detectable on modern basemaps, is remarkable. The affine transformation was applied with an overall RMS error of $2.83 \mathrm{~m}$. The spline function was not used in order to maintain the look and feel of the original 
map and to avoid the generation of local distortion owing to the unequal distribution of the points used. Using control points we were able to locate inherent inaccuracies that should be accounted for the original measurement and map construction process, and not for the map transformation method (Fig. 6).

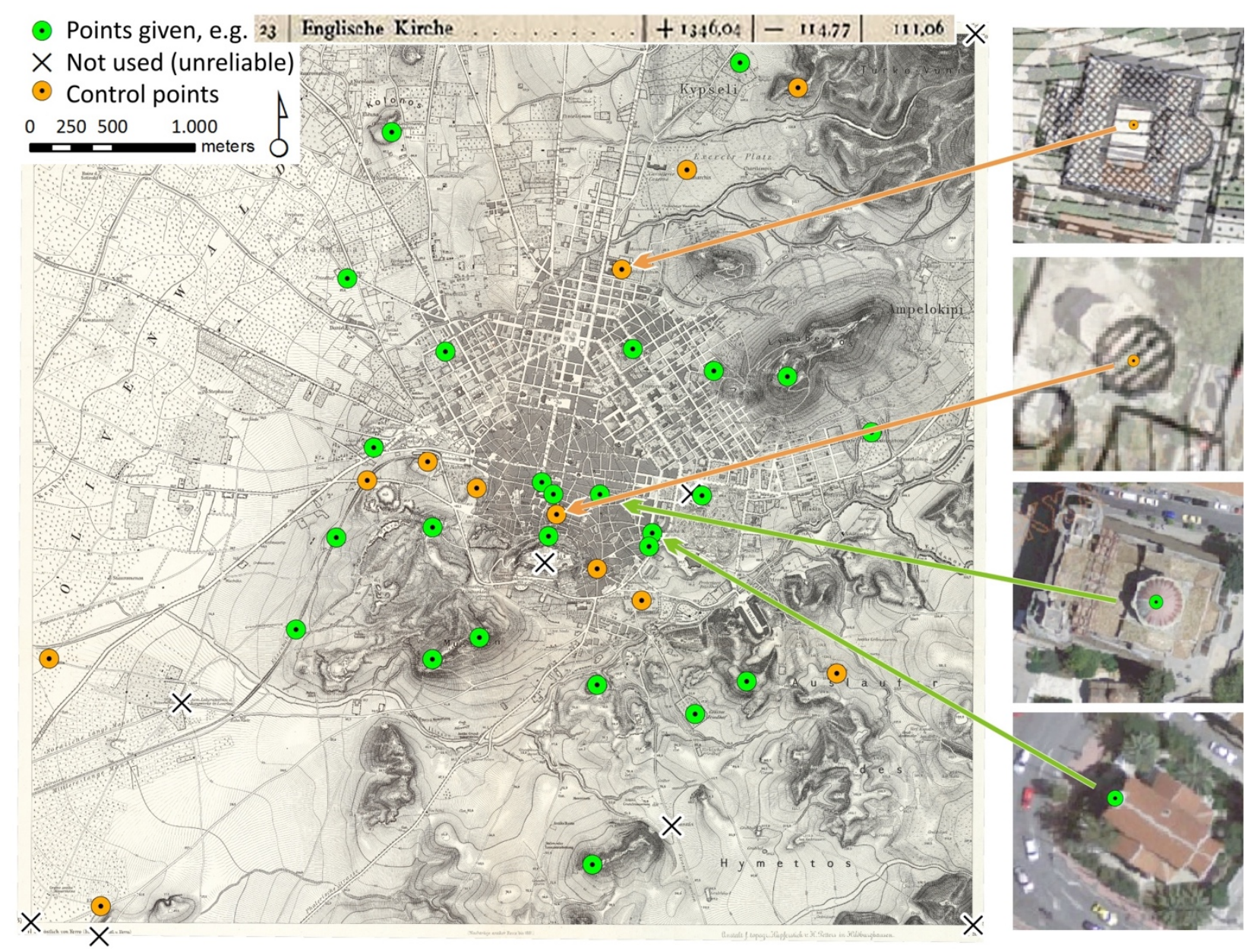

Figure 6. Georeferenced map sheet I from Karten von Attika [Curtius and Kaupert 1881]. Deviation of points used in the transformation procedure and control points are displayed on the satellite imagery (at right).

The final basemap used, dating to 1831-32, was prepared by S. Kleanthis and E. Schaubert. It is notably the earliest map of Athens after the Greek War of Independence and depicts the city layout before the finalization of the modern urban plan two years later. Its value is enormous, since its scale of 1:2000 allows for the depiction of very fine details in relation to the city layout and topographical evidence of buried ancient fortification structures. The original map was photographed in 9 parts, which were stitched together by $\mathrm{M}$. Korres for his subsequent publication on early maps of Athens [2010]. The georeferencing process has employed the observations made by Korres regarding: a) the map scale as derived by the measuring legend, $b$ ) the evident diagonal lines that break up the map in equal strips of $150 \mathrm{~m}, \mathrm{c}$ ) the less evident linear tracings that cut across the previous lines, and c) the 
detected deformations of the map related to humidity exposure. A grid of $75 \mathrm{~m}$ was prepared to correct the deformations related to humidity, using the intersections of the map lines. The spline transformation was used to make sure that the intermediate distance between lines is kept equal. The resulting map was georeferenced using around 40 ground control points, mostly monuments, topographical features and street intersections that could be traced in the different successive basemaps. The total affine RMS error was $2.75 \mathrm{~m}$. The map demonstrates remarkable accuracy in most parts of the city and has allowed us to digitize the course of the so-called Haseki Wall, built in the Late Ottoman period and demolished soon after Athens became the capital of the newly founded Greek state in 1834 (Fig. 7).

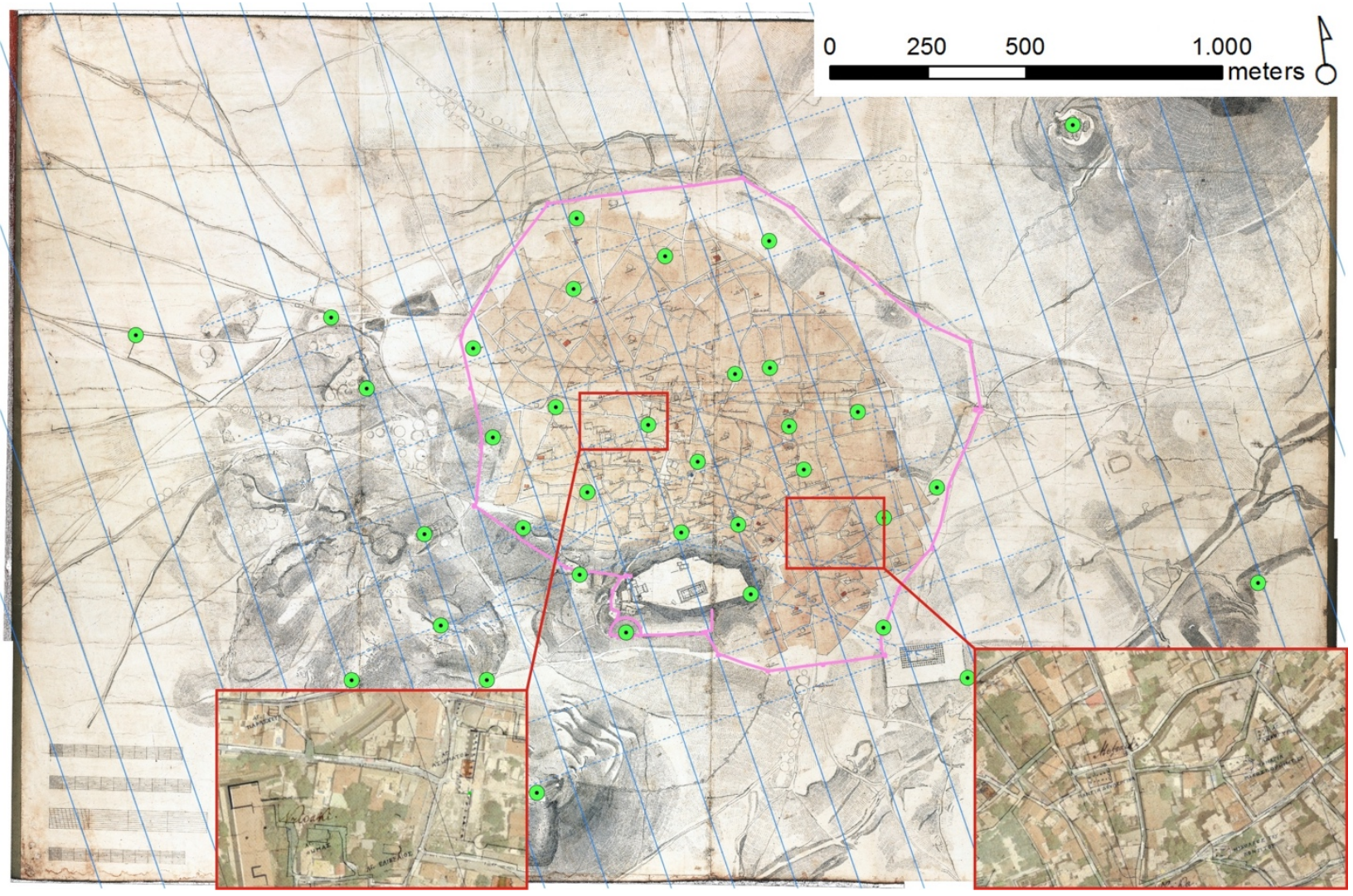

Figure 7. Georeferenced map of Athens by Kleanthis and Schaubert 1831-32 [Korres 2010]. The Haseki wall line is depicted in pink. Map lines are highlighted in blue. Details display the correspondence of the georeferenced map with satellite imagery.

Parts of four separately georeferenced cartographic basemaps have so far been prepared, with the successive record of the city transformations being traced backwards into the early 19th century. These basemaps may function as keyframes in a map time series that may be further enhanced [Koussoulakou and Andreanidou 2015; Koussoulakou et al. 2017]. Further improvements can be made by gradually filling the temporal gaps in between these keyframes, as well as by attempting to georeference additional earlier maps on the basis of the existing evidence. In Fig. 8, the map by L. F. 
S. Fauvel [Olivier 1807: Pl. 49], dating ca. 1787, has been georeferenced by employing the trace of the Haseki Wall, as digitized on the Kleanthis and Schaubert map, to limit edge effects and local distortion. The spline function is used to optimize for local accuracy and maintain map continuity and smoothness. The immediate gain, apart from a glimpse on the Ottoman town layout, is the location of the surviving remains of the ancient walls indicated on the map. Obviously, additional intermediate basemaps may produce more accurate results.

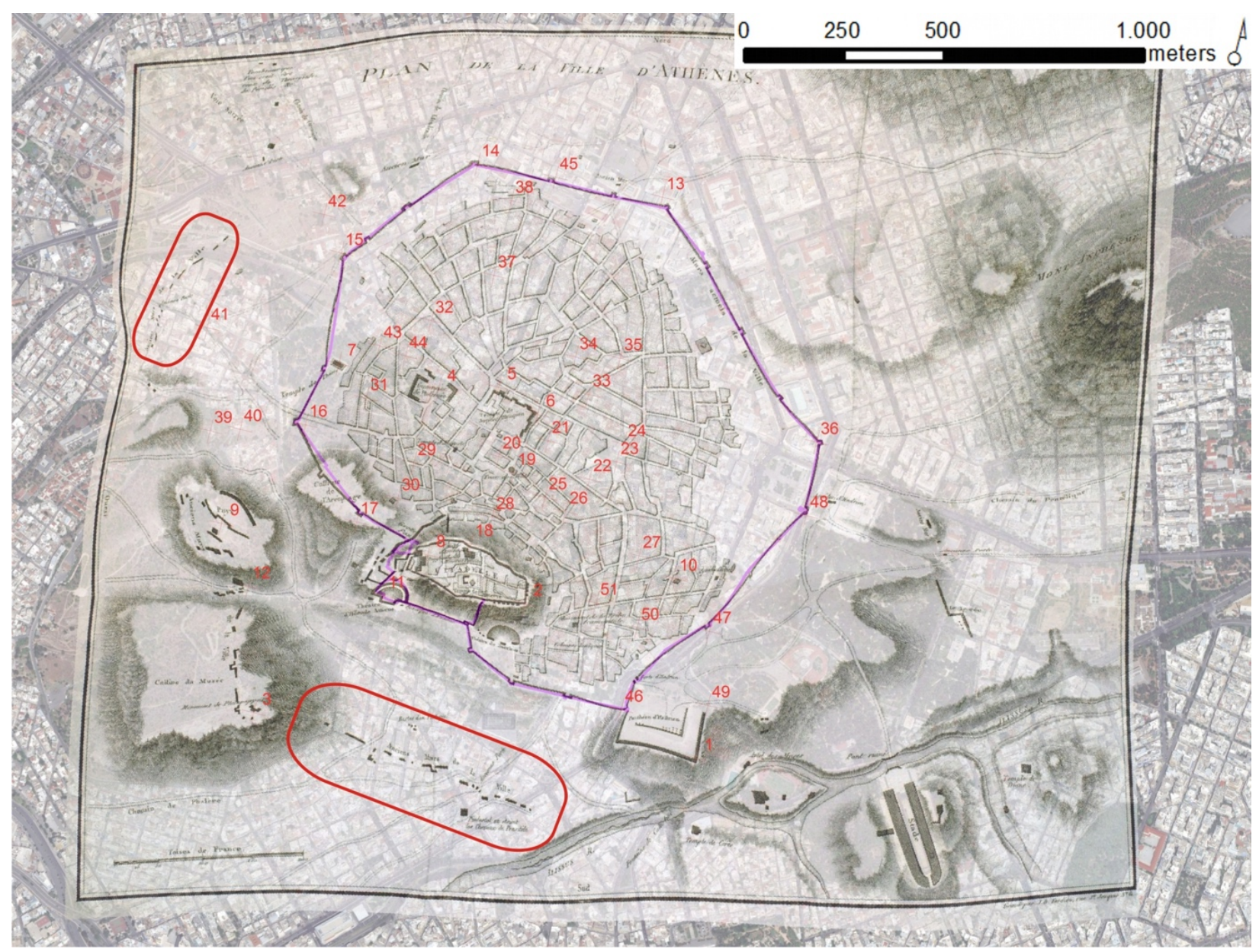

Figure 8. Registration of map by Fauvel (ca. 1787) [Olivier 1807: Pl. 49] showing reference points and Haseki Wall line (in pink) as digitized from the Kleanthis and Schaubert map. Surviving parts of the ancient wall are indicated on the map.

\subsection{Historical evidence}

With regard to historical evidence, various types of sources can be incorporated. There are sources in ancient Greek literature or inscriptions mentioning gate names, rebuilding interventions or repairs and relevant costs, as well as everyday activities taking place near or in relation to the walls. In addition, numerous references about the walls of Athens have been assembled by early travelers 
and antiquarians during their engagement with the classical ruins of the past in the form of writing and illustrations [Theocharaki 2015:37-120]. Even the daily press has provided interesting information, especially on 19th century archaeological fieldwork. [see www.lib.auth.gr/en/archaeological-events-reported-greek-press-1832-1932]. To these we may add a wealth of visual imagery from the 15th century onwards containing illustrations, sketches, paintings, photographs and, more recently, sound recordings, video and even mixed media.

Earlier evidence usually depicts surviving parts of the fortifications within their contemporary city context; sometimes they also document the appearance of the surrounding landscape. More recent evidence, especially video, often captures preserved remains for documentation purposes or during city sight-seeing tours. Visual evidence, in particular, can be repetitive in the sense that it may document different temporal benchmarks in the life-span of certain wall remains (Fig. 9).
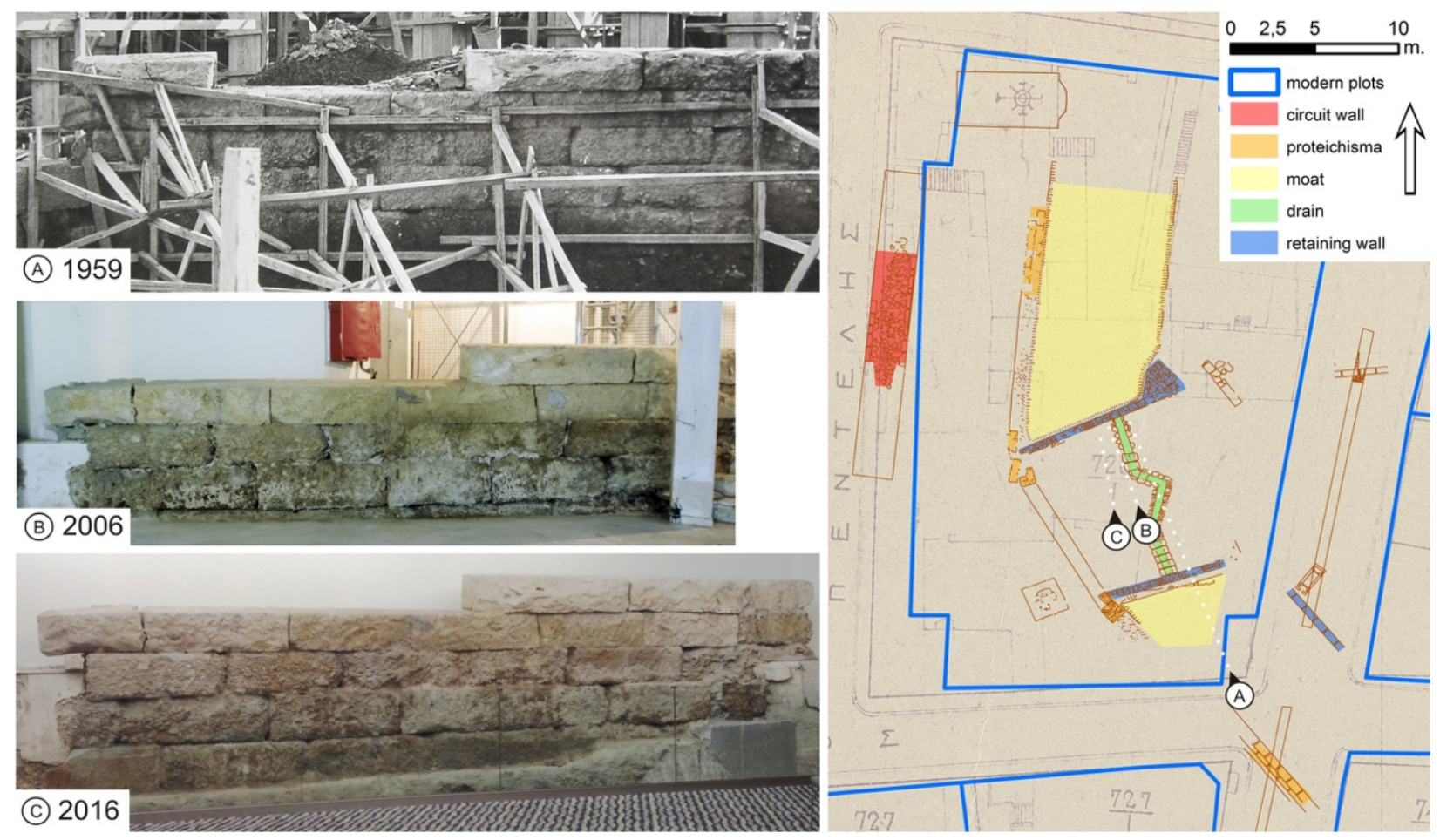

(C) 2016

Figure 9. At right: Excavation plot on 15-17 Mitropoleos Street (1959). Camera positions are shown in relation to surviving sections of the ancient fortifications and moat on top of a pre-excavation cadastral basemap (Division of City Planning and Urban Development, MoA). At left: Photographs of the retaining wall of the moat excavated in this plot document successive states of preservation: a) during construction of modern building after the excavation of the plot (Archive of the Archaeological Society at Athens), b) in the basement of the modern building [Theocharaki 2015: 318], and c) after recent renovation works in the same building to house a hotel (photo by A. M. Theocharaki).

All types of evidence, textual and visual, may be incorporated into the platform either in connection with specific locations of excavation interventions or as additional locations that provide supporting or supplementary information about the walls. These can be incorporated either as "Points of 
Interest" (POIs), associated with confined areas or specific locations, or as lines, associated with a journey that follows the wall line or connects several parts (Fig. 10).

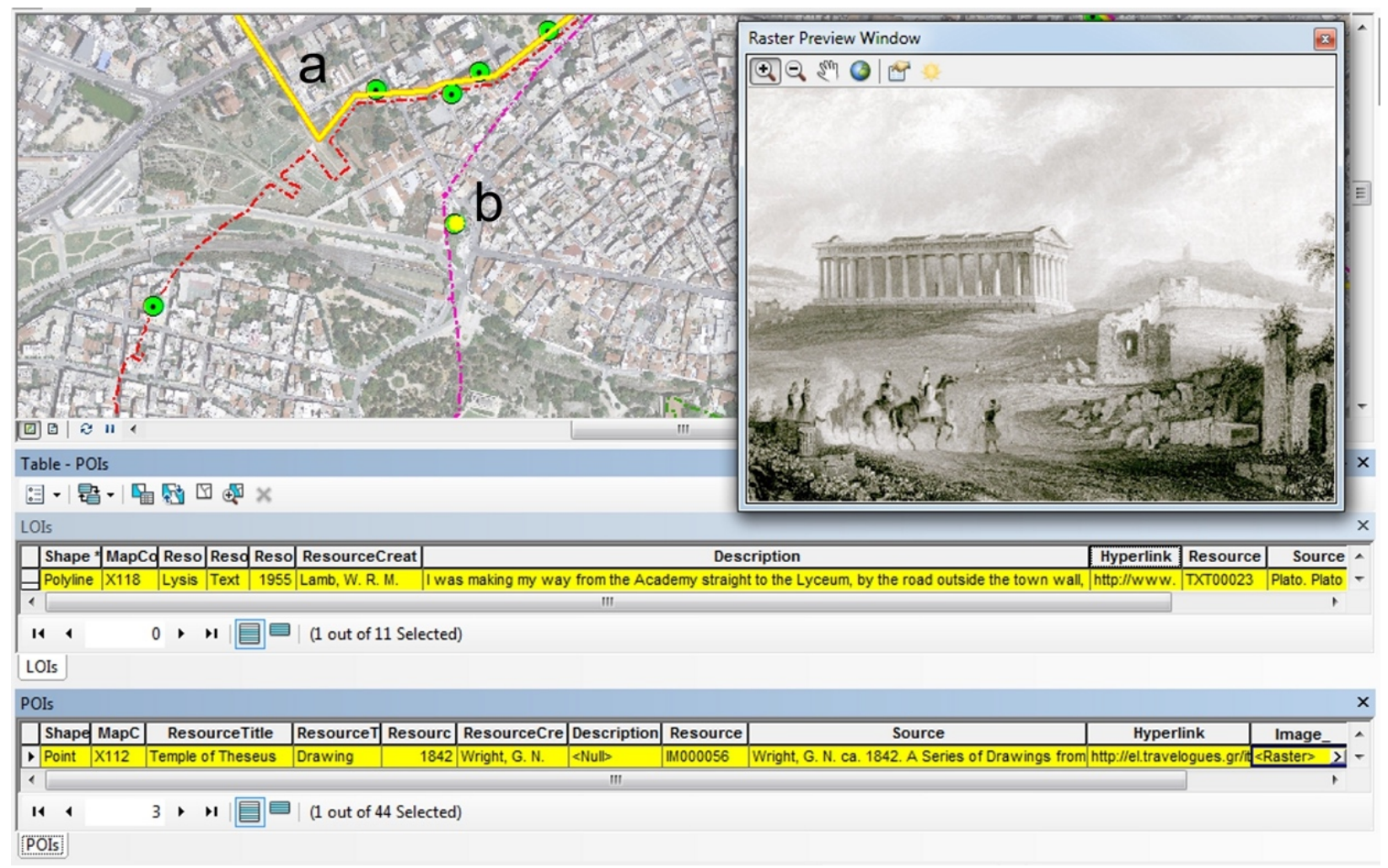

Figure 10. Example of geotagging of historical evidence associated with different fortification lines (red: the Themistoklean Wall, pink: the Haseki Wall, green: POIs): a) selected line highlighting the path taken by Socrates along the outer part of the walls, as mentioned in an excerpt from Plato's dialogue "Lysis" [203a], b) selected point approximating the drawing spot of the temple of Hephaistos in the Athenian Agora which includes surviving parts of the Haseki Wall (shown in thumbnail). Image source: Travelogues (Aikaterini Laskaridis Foundation).

\section{RESULTS}

The spatial integration of different information sources in an iterative manner has resulted in increased spatial accuracy and improved temporal connectivity of documented evidence on the citywall of Athens. In this sense, an enhanced geospatial data collection has been generated about the city-wall broadening the range of possible heritage perspectives and applications.

\subsection{Greater spatial and temporal resolution}

This approach has allowed us to position archaeological and topographical accounts bearing evidence for wall remains with greater accuracy (Fig.11). 


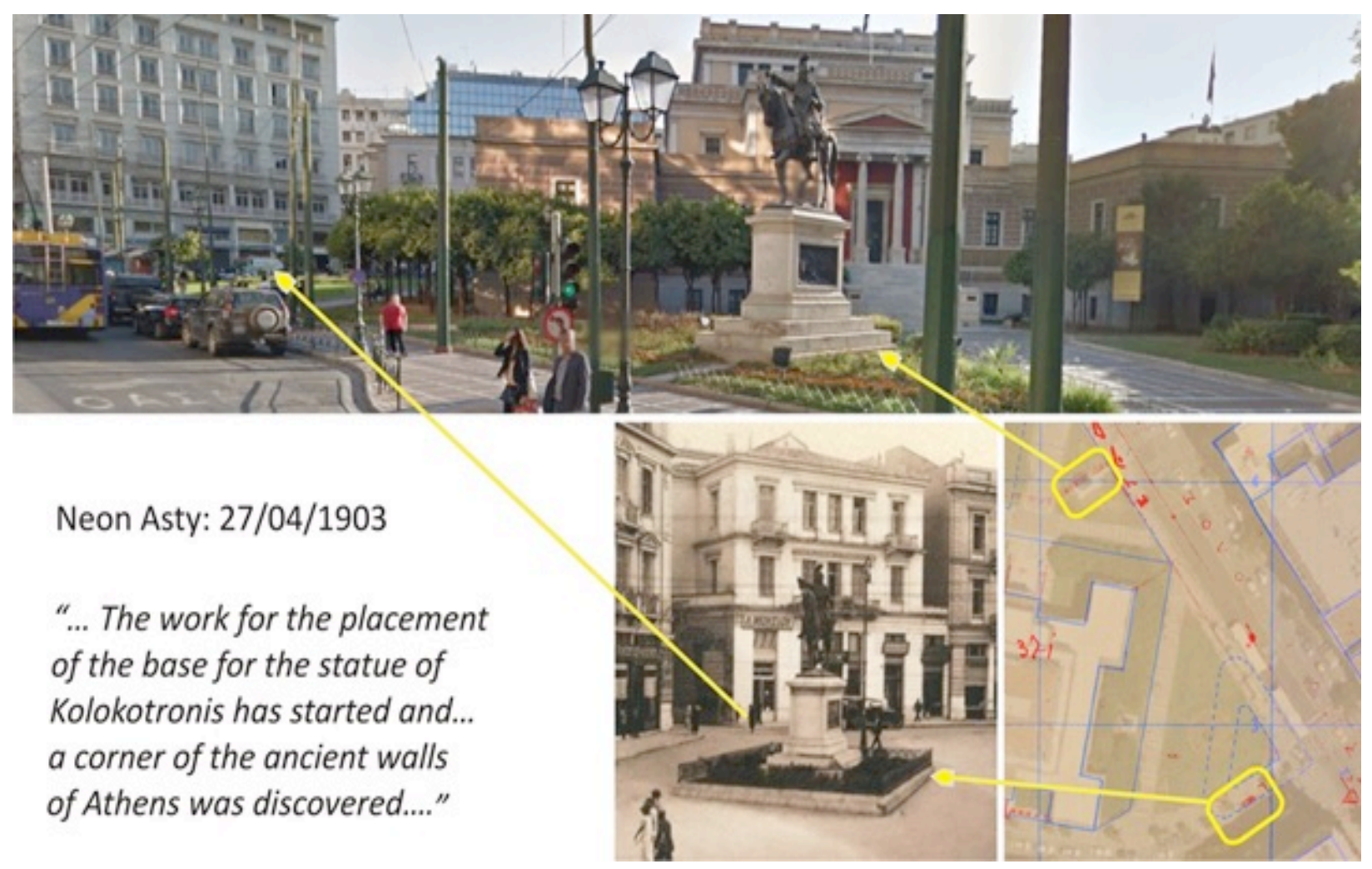

Figure 11. Top image showing current location of statue of Th. Kolokotronis (a pre-eminent leader of the Greek War of Independence) (GoogleEarth Streetview: 10/2014). The source text refers to wall section retrieved before relocation of the statue. Combination of sources (Image from the ERT S.A. Photographical Archive 0000001192/1.1.4.7 and cadastral map (Division of City Planning and Urban Development, MoA) has allowed the correct retrieval of the original position of the statue and of the walls respectively.

It has also enabled us to monitor changes in plots and to decipher the excavation record of interventions spanning an entire century for many blocks, whose precise location-especially the earlier ones dating to the late 19th century-could only be accurately located using the combined map backgrounds (Fig. 12).

Another benefit of this approach relates to the identification of parts of the ancient wall that were visible or detectable through their topographical trace before the building booms of modern Athens (mid-19th and second half of the 20th centuries). Early maps (especially those of Kleanthis-Schaubert and Curtius-Kaupert) contain evidence (structures or topographic breaklines) potentially related to wall remains that are either standing or buried in situ. The spatial correspondence of the remains and traces of buried structures can be explored in relation with the current excavation record; new areas not yet investigated can be further located (Fig. 13). 


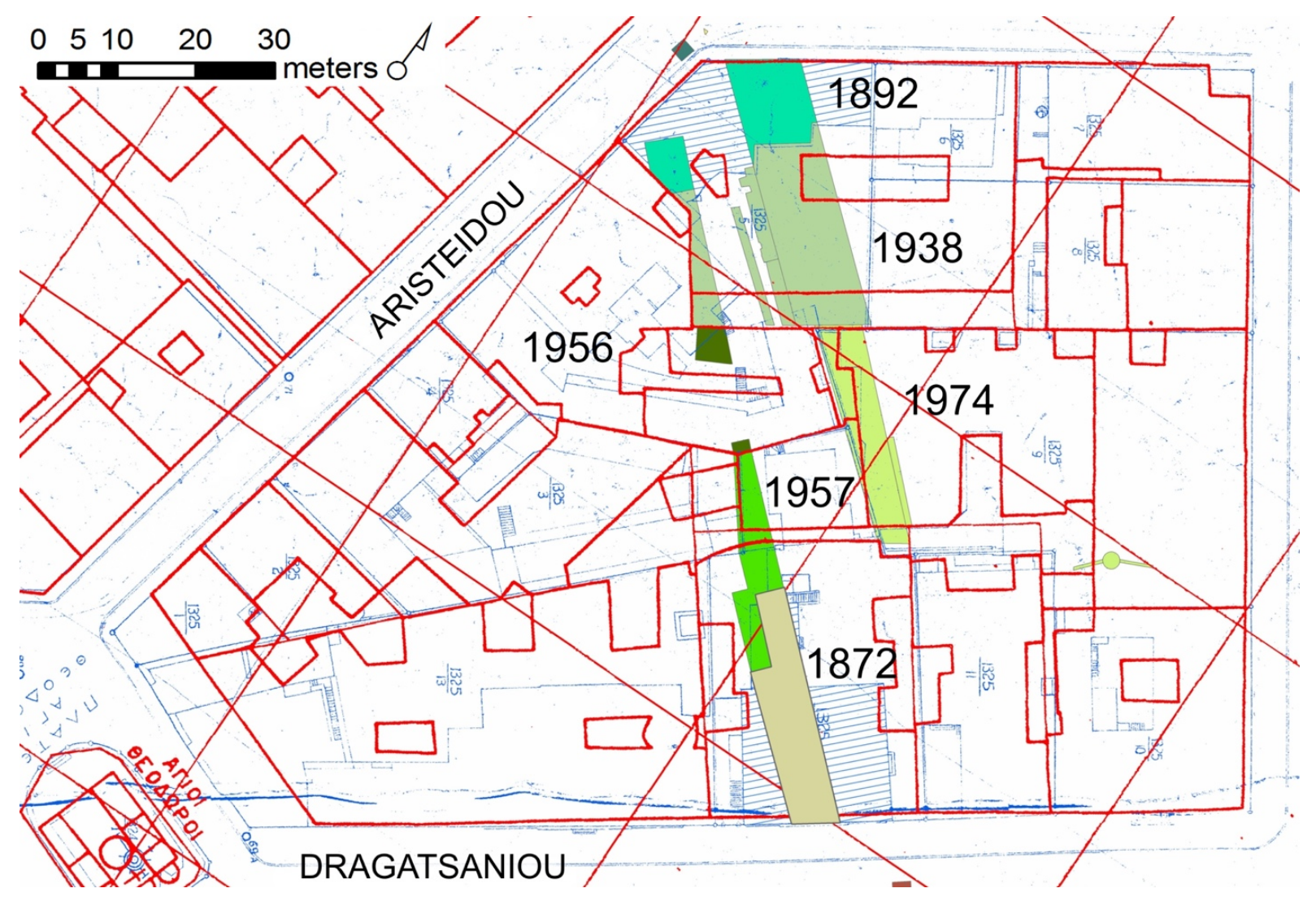

Figure 12. City block between Aristeidou and Dragatsaniou Streets. Successive excavations that have revealed remains of the Athenian fortification wall are indicated on top of basemaps dating to 1936 (in blue - Division of City Planning and Urban Development, MoA) and 1972-76 (in red - Ministry of Public Works).

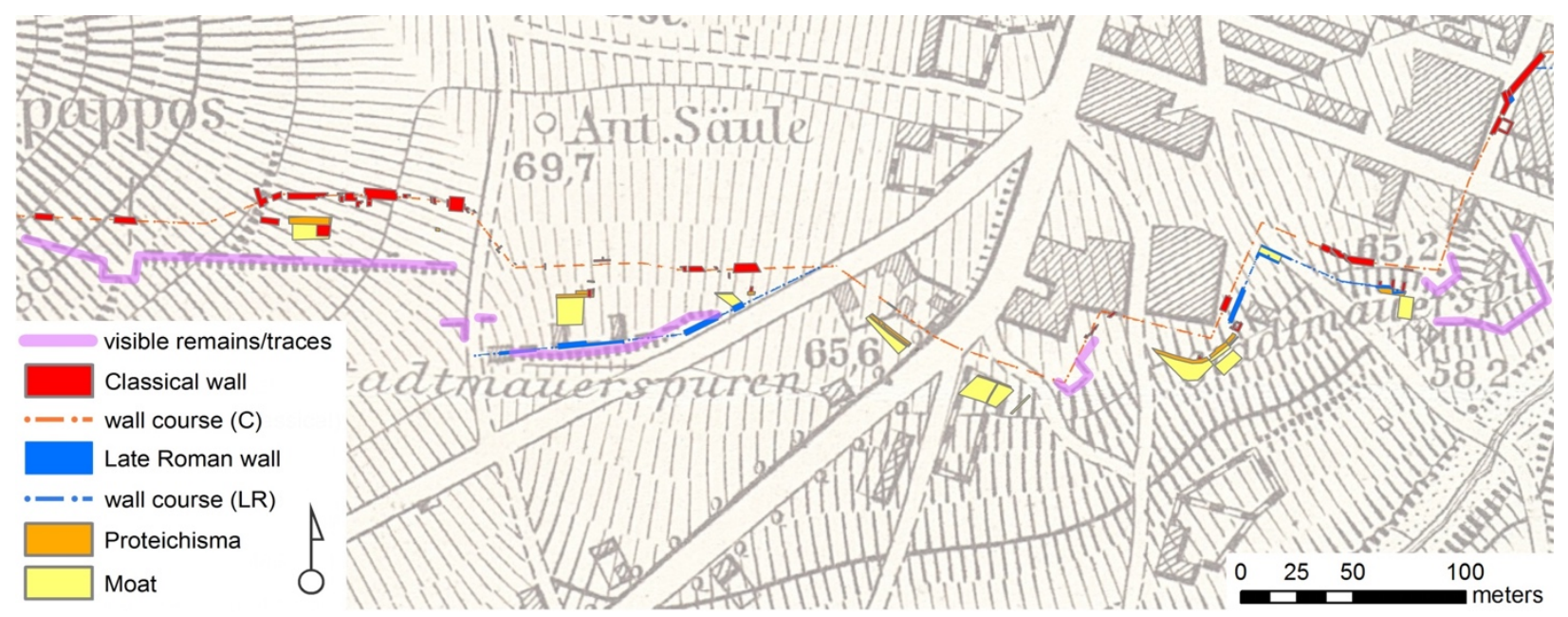

Figure 13. Detail from sheet I in Karten von Attika [Curtius and Kaupert 1881] with visible wall remains at the time collated with excavated wall features. 


\subsection{Connection with graphical evidence}

Another exciting opportunity relates to the positioning of historical photographs and/or past representations of lost fortification remains onto the modern city layout. Correlating points on historical photographs with their counterparts on georeferenced historical maps of the same period makes possible the orientation and positioning in space of the original images. Positioned images can be projected onto Google Earth street map view to create a combined multi-temporal view [Tsioukas et al 2015]. The idea to combine maps and imagery can be extended to earlier graphical representations, so that the location of the remains depicted in an artwork are approximated (Fig. 14). The procedure could open up further possibilities to extract metric information of lost architectural features.

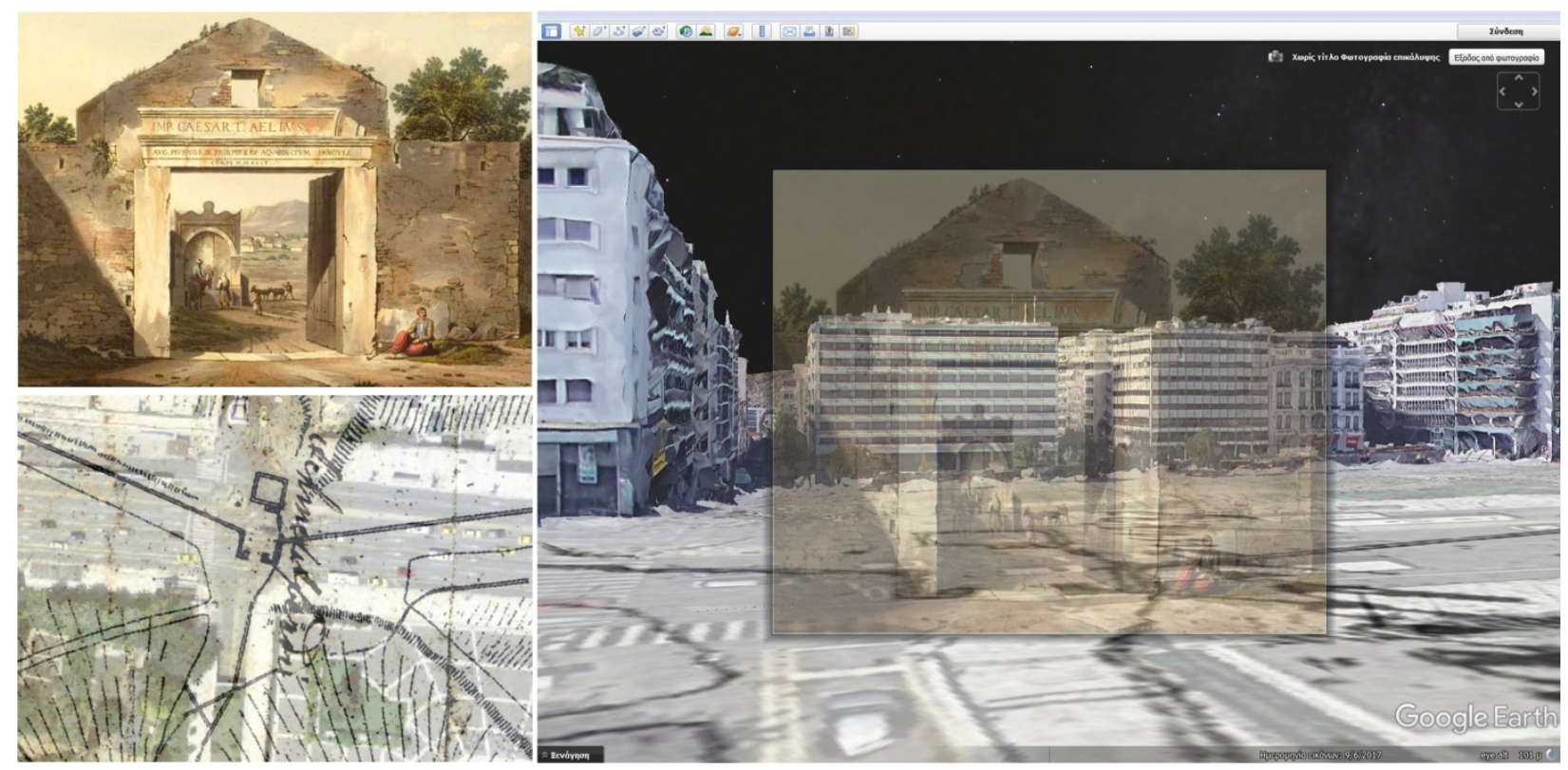

Figure 14. Illustration of the "Gate of Mesogeia" of the Haseki Wall, by E. Dodwell (1805) (at top left). The gate is located on the georeferenced map by Kleanthis and Schaubert (1831-32) [Korres 2010] (at bottom left), allowing for its approximate positioning on Amalias Ave. (Syntagma Sq.) in Google Earth Streetview (at right).

\subsection{Cartographic representation and data exploration}

At the end of this iterative process, all relevant content is being organized within a geospatial dataset. The dataset contains basic elements, such as a raster/basemap catalogue, a feature dataset including wall courses as lines, archaeological evidence as polygons, and graphical imagery as POIs or lines. The end-user will be able to navigate within the cartographic environment, select features or perform queries using different variables (e.g., wall section type, chronology, preservation condition and accessibility) returning results from all data categories (Fig. 15). A web-interface is under development to present research results to the public (Fig. 16). A prototype version has been compiled using several spatial and content management libraries and tools. 
2:192 M. Katsianis et al.

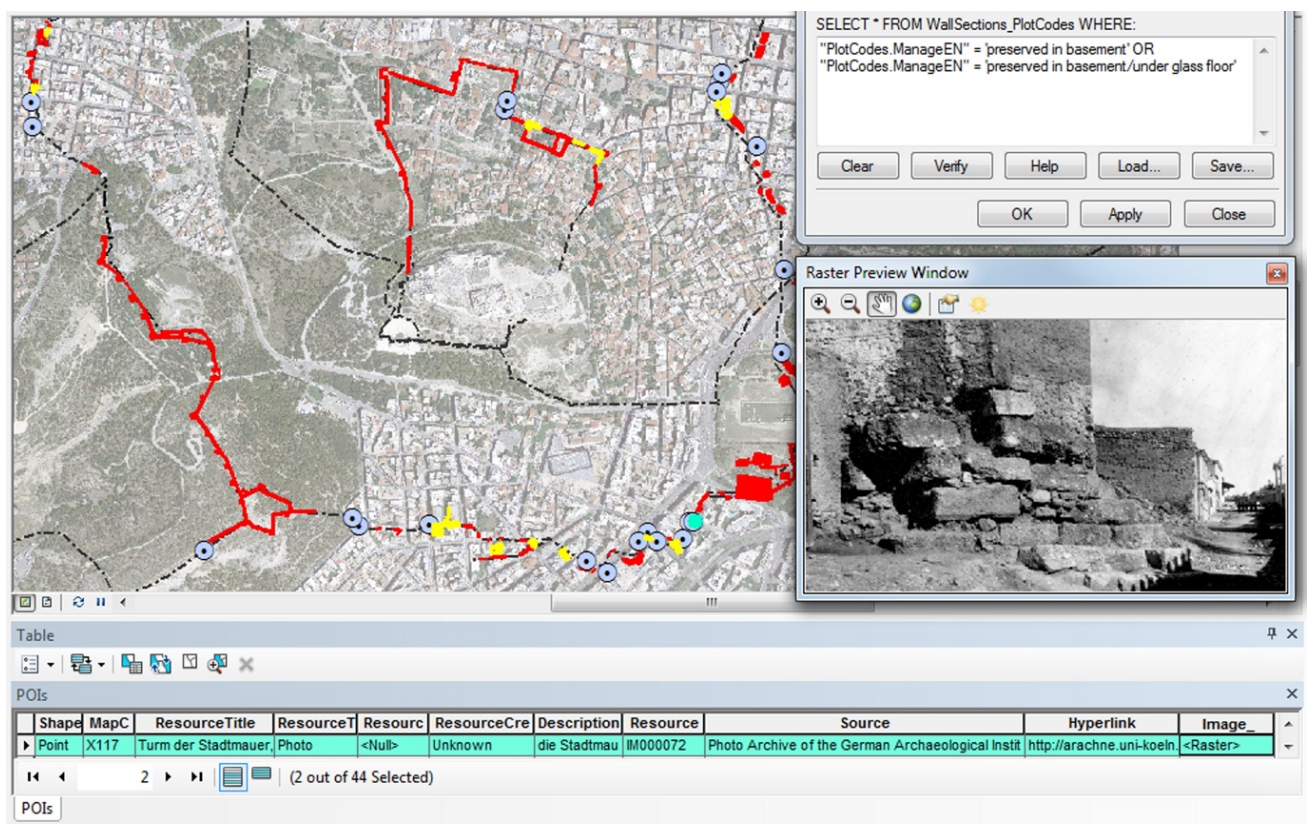

Figure 15. Example of fortification evidence showing locations with surviving wall remains. Different wall courses are shown as black dotted lines. Archaeological remains are indicated as polygons and POls as points. Query results show areas with surviving evidence in residential basements (in yellow). Selection of POI (in light blue) in the vicinity opens up the source record and archival image (shown in thumbnail - Photo Archive of the German Archaeological Institute (DAl-Athens), neg. D-DAI-ATH-Athen Bauten 398).

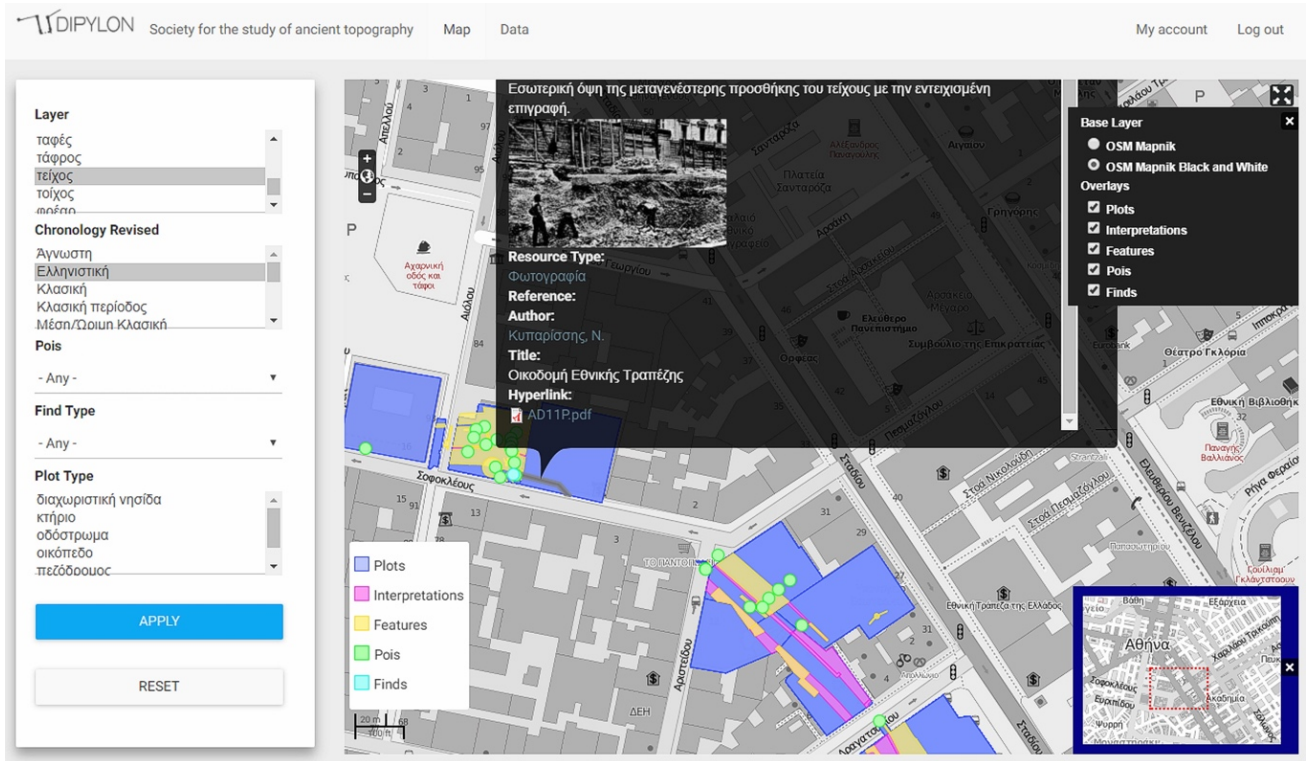

Figure 16. Section of the dataset published within a Web Mapping Application (WMA). On-screen feature selection returns the record of the selected geometry and associated media (Application development by G. Panagiotopoulos). 
PostgreSQL with the PostGIS extension has been employed to store the data. The database schema has been constructed in Drupal, allowing for web input forms for attribute data. The relevant geometry can be uploaded to the database through the Drupal web forms or the QGIS software and is automatically linked to attribute data on the basis of unique identifiers. A GeoServer connects to the database and exports the data to Web Mapping Services (WMS) and Web Feature Services (WFS). The front-end client is developed using the Openlayers library to get the WMS and WFS services and display the spatial data on different basemaps, while offering some non-spatial query capabilities.

\section{CONCLUSIONS - FUTURE PROSPECTS}

Our journey into the study of the fortifications of Athens has revealed that combining data from different sources and disciplines through digital mapping has the potential to re-activate the informational capacity of segregated evidence and improve the understanding of the diachronic transformations of the fortifications of Athens.

In this regard, the geospatial collection can lead to broader heritage perspectives, as the integration of all this new information within a location-based framework may allow the scholar:

- $\quad$ to switch between spatial scales;

- $\quad$ to explore evidence from different chronological periods;

- to have access to all supportive material, such as textual information, graphical representations, and composite geo-located visualizations.

Further steps aim primarily:

- to investigate questions related to the management of surviving archaeological remains and identify wall sections belonging to multiple fortification phases;

- to enhance the existing dataset using additional data types, such as 3D models of excavated remains;

- $\quad$ to explore alternative web-sharing options, especially with regard to Narrative Cartography.

\section{ACKNOWLEDGEMENTS}

The authors gratefully acknowledge the Division of City Planning and Urban Development of the Municipality of Athens for their permission to produce digital copies of selected map sheets from the pre-1936 cadastral registration held in their archives. Also, Melissa publishing house and Manolis Korres for granting us copies from the original photographic documentation of the Kleanthis and Schaubert map of Athens 1831-32. DAI, ERT S.A., the Archaeological Society at Athens and the A. Laskaridis Foundation for their permission to include images from their archives here. Finally, we wish to acknowledge the anonymous referees for their useful comments. 
2:194 M. Katsianis et al.

\section{REFERENCES}

Chryssoula Boutoura and Evangelos Livieratos. 2006. Some Fundamentals for the Study of the Geometry of Early Maps by Comparative Methods. e-Perimetron, 1 (1), 60-70. Retrieved December 12, 2017 from http://www.eperimetron.org/vol_1_1/boutoura_livieratos/1_1_boutoura_livieratos.pdf

Leda Costaki. 2006. The intra muros Road System of Ancient Athens. PhD thesis: University of Toronto.

Ernst Curtius and Johann A. Kaupert. 1881. Karten von Attika, Berlin: Heft I. Retrieved December 12, 2017 from http://digi.ub.uni-heidelberg.de/diglit/curtius1878

Forum on Information Standards in Heritage (FISH). 2019. FISH Vocabularies, Available from http://www.heritage-standards.org.uk/fish-vocabularies/

The Getty Research Institute. 2018. Art \& Architecture Thesaurus® Online. Available from http://www.getty.edu/research/tools/vocabularies/aat/

Irene Demetriadou. 2012. Primitive Athens (1100-480 B.C.): Observations on the Domestic Development and the Cemeteries (Phd thesis: University of Athens. In Greek). Retrieved December 12, 2017 from https://www.didaktorika.gr/eadd/handle/10442/33253

René Ginouvès. 1998. Dictionnaire méthodique de l'architecture grecque et romaine. Tome III. Espaces architecturaux, bâtiments et ensembles. Préface de René Ginouvès et Marie-Christine Hellmann. Rome : École Française de Rome.

René Ginouvès and Roland Martin. 1985. Dictionnaire méthodique de l'architecture grecque et romaine. Tome I. Matériaux, techniques de construction, techniques et formes du décor. Rome: École Française de Rome, 1985.

Walther Judeich. 1931. Topographie von Athen. Munich: C.H. Beck.

Dimitris Karydis. 1981. Town Planning of Ottoman Athens. PhD Thesis: National Technical University of Athens (in Greek). Retrieved December 12, 2017 from https://www.didaktorika.gr/eadd/handle/10442/11528

Manolis Korres. 2008. Creation Content and Value of Kaupert's Maps of Attica. Athens: Melissa (in Greek).

Manolis Korres. 2010. The First Maps of the City of Athens. Athens: Melissa (in Greek).

Alexandra Koussoulakou and Ioanna Andreanidou. 2015. On Common Ground: Georeferencing a Time Sequence of Historic Maps. Presented at the 10th Jubilee International Workshop on Digital Approaches to Cartographic Heritage. Corfu, May 27-29. Retrieved December 12, 2017 from http://users.auth.gr/ kusulaku/Kous_Andr_Corfu-2015.gif

Alexandra Koussoulakou, Ioannis Mitzias, and Ioanna Andreanidou. 2017. Mapping the City Walls of Thessaloniki through Time. Presented at the 12th International Conference on Digital Approaches to Cartographic Heritage. Venice, April 26-28. Retrieved December 12, 2017 from http://users.auth.gr/ kusulaku/Kous-Mitz-Andr_VeniceDTCH2017.gif

Maria Lagogianni-Georgakarakos, and Thodoris Koutsogiannis eds. 2015. "A dream among Splendid ruins." Strolling through the Athens of Travelers 17th-19th century. Athens: Ministry of Culture, Education and Religious Affairs - National Archaeological Museum.

Evangelos Livieratos, Chryssoula Boutoura, Alexandra Koussoulakou, Nopi Ploutoglou, Maria Pazarli, and Angeliki Tsorlini. 2013. Karten von Attica: A Major German Contribution to Greek Cartographic Heritage and its Digital Approach. In: Proceedings of the 25th International 
The City Walls of Athens $\quad 2: 195$

Cartographic Conference, Dresden, Germany, 25-30th August. Retrieved December 12, 2017 from https://icaci.org/files/documents/ICC_proceedings/ICC2013/_extendedAbstract/423_proceeding. pdf

Guillaume Antoine Olivier. 1807. Atlas pour servir au voyage dans l'Empire Othoman, l'Égypte et la Perse, Paris 1807.

Anastassios Orlandos and John Travlos. 1986. Dictionary of Ancient Architectural Terms. Library of the Archaeological Society at Athens, 94. Athens: The Archaeological Society at Athens (in Greek).

Liana Parlama and Nikos Stampolidis eds. 2000. Athens: The City Beneath the City: Antiquities from the Metropolitan Railway Excavations. Athens: Museum of Cycladic Art.

Irwin Scollar. 2002. The Map Maker's "Tower of Babel", AARGnews 24: 14-25.

Anna Maria Theocharaki. 2011. The Ancient Circuit Wall of Athens: Its Changing Course and the Phases of Construction, Hesperia 80 (1), 71-156. Retrieved December 12, 2017 from http://www.ascsa.edu.gr/pdf/uploads/hesperia/hesp.80.1.0071.pdf

Anna Maria Theocharaki. 2015. The Ancient Walls of Athens. Athens: Greek Epigraphic Society (in Greek).

John Travlos. 1971. Pictorial Dictionary of Ancient Athens. London.

Vassilios Tsioukas, Alexandra Koussoulakou, and Tamás Jancsó. 2015. Falling into Place:

Orientation and Vewing of Past Cityscapes in 3D space, e-Perimetron, 10 (1), 30-41. Retrieved December 12, 2017 from

http://www.e-perimetron.org/Vol_10_1/Tsioukas_Koussoulakou_Jancso.pdf

Nikos Tsoniotis. 2008. New Data for the Late Roman Wall of Athens. Stavros Vlizos, ed. Athens during Roman Times: Recent Discoveries and New Research. Athens: Benaki museum: 55-74 (in Greek).

Aggeliki Vavylopoulou-Charitonidou, Eleni Makri, and Konstantinos Tsakos. 1988. Rizokastro. Surviving Remains. New Observations and Revised Dating. Deltion of the Christian Archaeological Society 14 (1987-1988): 329-366 (in Greek). Retrieved December 12, 2017 from https://ejournals.epublishing.ekt.gr/index.php/deltion/article/view/4658/4434

Received September 2018; revised October 2018; accepted December 2018. 